\title{
Cystatin C is a reliable marker for estimation of GFR in renal Transplantation: validation of a new turbidimetric assay using monospecific sheep antibodies
}

Anne-Sophie Bargnoux ${ }^{1,2}$, Etienne Cavalier ${ }^{3}$, Jean-Paul Cristol ${ }^{1,2}$; Noémie Simon ${ }^{1}$, Anne-Marie Dupuy ${ }^{1}$, Valérie Garrigue ${ }^{4}$, Stéphanie Badiou ${ }^{1,2}$, Pierre Delanaye ${ }^{5}$, Georges Mourad $^{4}$ and SFBC "Biology of renal function and renal failure" working group

${ }^{1}$ Department of Biochemistry, University of Montpellier 1, Montpellier, France

${ }^{2}$ UMR 204 Nutripass, IRD, Université Montpellier 1, Université Montpellier 2, SupAgro, Montpellier, France

${ }^{3 .}$ Department of Clinical Chemistry, University of Liege, University Hospital of Liege, Liege, Belgium

4. Department of Nephrology Transplantation and Peritoneal Dialysis, University of Montpellier 1, Montpellier, France

${ }^{5}$ Department of Nephrology, Transplantation and Dialysis, University of Liege, University Hospital of Liege, Liege, Belgium

Running Title: Cystatin C and GFR in renal transplantation

Address for correspondence:

Jean-Paul Cristol

Department of Biochemistry,

Lapeyronie University Hospital

191 Avenue du Doyen Gaston Giraud, 34295 Montpellier cedex 5, France.

Phone : + 33467338 314, Fax : + 33467338 393,

E-Mail: jp-cristol@chu-montpellier.fr

Received May 21, 2010; accepted September 6, 2010 


\section{Abstract :}

Background: The potential use of Cystatin C was recently assessed in kidney transplantation. A new particle-enhanced turbidimetric immunoassay (PETIA) that uses sheep antibodies (Binding Site Human Cystatin C immunoassay) has been developed. Analytical performance of this new assay was evaluated. Clinical relevance was determined by comparison with a reference method in a cohort of kidney transplant patients.

Patients and methods: First, the analytical performance of the Binding Site cystatin $\mathrm{C}$ kit was tested on SPAPLus ${ }^{\circledR}$ and Hitachi ${ }^{\circledR}$ analyzers. Second, a comparison study was performed using SPAPLus ${ }^{\circledR}$ analyzer against two other cystatin C methods (the Siemens-PENIA method on BNII ${ }^{\circledR}$ and the Dako-PETIA application on Olympus AU640 ${ }^{\circledR}$ ). Third, the glomerular filtration rate (GFR) was estimated using several predictive cystatin C- and creatinine-based equations and compared to GFR measured by an isotopic method ( $\left.{ }^{99 \mathrm{~m}} \mathrm{Tc}-\mathrm{DTPA}\right)$. These predictive algorithms were analyzed with respect to bias, precision and accuracy.

Results: Total intra-assay and inter-assay coefficients of variation were below 5\%. Values obtained with the SPAPLUS ${ }^{\circledR}$ correlated with the Siemens-PENIA and the Dako-PETIA methods. The creatinine and cystatin C-based equation allowed reliable assessment of GFR in our population of renal transplantation.

Conclusions: The use of algorithms based on cystatin $\mathrm{C}$ and creatinine could provide a reliable estimate of GFR in kidney transplantation.

Key words: Cystatin C, renal transplantation, glomerular filtration rate, predictive equations 


\section{Introduction}

Assessing renal function accurately is of particular importance in renal transplantation as detection of graft dysfunction is essential for early diagnostic and therapeutic intervention. In this context, there is a growing interest in cystatin $\mathrm{C}$ as a marker of renal function when used to estimate the glomerular filtration rate (GFR) (1). Conflicting data has been published about the relative accuracy of various equations using creatinine or cystatin to predict GFR in

transplant recipients (2). Recently, Stevens et al. (3) developed a new cystatin C-based GFR formulas using cystatin $\mathrm{C}$ alone, and cystatin $\mathrm{C}$ in combination with creatinine and demographic coefficients in 3418 individuals with chronic kidney disease (CKD).

Currently, particle-enhanced immunonephelemetry (PENIA) or immunoturbidimetry (PETIA) methods are available for measuring cystatin C in serum. Most of cystatin C-derived equations to estimate GFR are based on Siemens antibodies using PENIA measurements $(3,4)$ or Dako antibodies using PETIA $(5,6)$. A new particle-enhanced turbidimetric immunoassay using mono-specific sheep antibodies on the SPAPLUS ${ }^{\circledR}$ analyzer has been developed by the Binding Site group Ltd and approved by the FDA.

The aim of this study was 1) to evaluate the analytical performance of this novel cystatin C kit using the SPAPLus ${ }^{\circledR}$ and Roche Hitachi ${ }^{\circledR} 917$ instruments; 2) to compare this new assay with already established cystatin $\mathrm{C}$ methods (PENIA method using Siemens reagents on BNII ${ }^{\circledR}$ and the Dako-PETIA application on Olympus AU640 ${ }^{\circledR}$ ); 3) to compare estimated GFR (eGFR) values from creatinine, cystatin $\mathrm{C}$, or combined creatinine and cystatin $\mathrm{C}$ based equations to the GFR measured (mGFR) using an isotopic reference method $\left({ }^{99} \mathrm{Tc}-\mathrm{DTPA}\right)$ in a population of kidney transplant recipients. 


\section{Patients and Methods}

\section{Study Design}

Analytical performance of the Binding Site cystatin $\mathrm{C}$ method was performed using the SPAPLUS $^{\circledR}$ analyzer (Binding Site, Birmingham, UK) in Montpellier center and a Hitachi ${ }^{\circledR} 917$ analyzer (Roche Diagnostics, Mannheim Germany) in Liege Center. In addition, measurement of five similar pools was performed simultaneously in the two centers. A correlation study was performed between the Binding Site Cystatin C on the SPAPLuS ${ }^{\circledR}$ and two well established methods: the Siemens-PENIA method on the BNII ${ }^{\circledR}$ and the DakoPETIA method on an Olympus AU640 ${ }^{\circledR}$.

In addition to this methodological evaluation, the clinical relevance of the SPA PLUS ${ }^{\circledR}$ assay was assessed by comparison of the eGFR using a cystatin C-based formula with isotopic measurement of GFR in kidney transplant recipients.

\section{Methods}

The Binding Site Cystatin C method was performed using a PETIA method on the SPAPLUS ${ }^{\circledR}$ (Binding Site, Birmingham, UK) or a Hitachi ${ }^{\circledR} 917$ analyzer (Roche Diagnostics, Mannheim Germany) according to the manufacturer's instructions. Cystatin $\mathrm{C}$ latex reagents from the Binding Site consists of monospecific sheep antibodies coated onto polystyrene latex particles. Calibrators and controls consisted of pooled human serum and were supplied in stabilized liquid form by the manufacturer. The assay is performed using a six point calibration curve covering the range $0.40-7.35 \mathrm{mg} / \mathrm{L}$ (produced with a calibrator set containing 6 concentrations of pre-diluted, ready to use calibrators). The following protocol for measuring cystatin $\mathrm{C}$ was used on the two analyzers. A standard 1/10 sample dilution is 
done automatically by the analyzer using a specific diluent. The diluted sample is incubated with R1 for 5 mins on the SPAPLUS ${ }^{\circledR}$ ( 2 mins on Hitachi ${ }^{\circledR}$ ), followed by the addition of R2 and allowed to react for another 5.5 mins. on the SPAPLUS ${ }^{\circledR}\left(10\right.$ mins on Hitachi $\left.{ }^{\circledR}\right)$. There are preheating and washing cycles and the total time to first result is approximately 14 mins. The reaction temperature is $37+/-0.1^{\circ} \mathrm{C}$ and the assay is an end point assay. The wavelength of the incident beam is $600 \mathrm{~nm}$. If a result is more than $7.35 \mathrm{mg} / \mathrm{l}$, the instrument does an automatic 1/20 sample dilution. This new method has not been validated for measurement of cystatin $\mathrm{C}$ in urine.

N Latex Cystatin C reagents from Siemens are polystyrene particles coated with rabbit antibodies for the quantitative determination of cystatin $\mathrm{C}$ using particle-enhanced immunonephelometry with the $\mathrm{BN}^{\circledR}$ systems (Siemens, Marburg, Germany).

Dako Cytomation Cystatin C reagents (Dakocytomation, Glostrup, Denmark) were used in a PETIA method with the AU640 ${ }^{\circledR}$ Biochemistry analyzer (Olympus, Rungis, France). This method uses rabbit polyclonal antibodies directed against cystatin $\mathrm{C}$ coupled to polystyrene particles.

\section{Assay Procedure}

Analytical Performances

Intra-assay $(\mathrm{n}=30)$ and inter-assay precision (3 determinations per day over 10 consecutive days) was assessed using Human cystatin C low control (approximately $1 \mathrm{mg} / \mathrm{L}$ ) provided by the manufacturer and measured using the SPAPLuS ${ }^{\circledR}$ and Hitachi ${ }^{\circledR}$ instruments. Linearity was evaluated by successive dilutions of sera from patients with high cystatin $\mathrm{C}$ concentration. Correlation between serum and heparinized plasma was performed using 50 samples on the $\mathrm{SPA}_{\mathrm{PLUS}}{ }^{\circledR}$ analyzer. Serum samples were obtained using $5 \mathrm{~mL}$ plain tubes and plasma was obtained using lithium heparin tubes without s silicon gel barrier (Becton 
Dickinson, Vacutainer Systems, Plymouth, England). After centrifugation at $1000 \mathrm{~g}$ for 15 min, samples were stored at $-80^{\circ} \mathrm{C}$.

Panel Determination

As a part of the multicenter evaluation of creatinine and cystatin reagents performed by the "Biology of renal function and renal failure" working group (SFBC/SN/SFD)", a panel of five serum pools, provided by the laboratory of Pr Galteau (Centre de Médecine Préventive, Nancy, France), was assayed.

Measurements using the panel were performed with a single batch of reagents following a new calibration. The 5 pools were assayed in 3 separate runs per day; the low control provided by the manufacturer was run at the start and/or the end of the run in order to verify the run. This test was conducted over 3 consecutive days ( 1 aliquot thawed each day). The same procedure was carried out in Liege and Montpellier.

\section{Method Comparison}

For method comparison studies, specimens from 99 consecutive renal transplant patients (64 men, 35 women) with a mean age of $50.7 \pm 12.4$ years were collected. The median time since transplantation was 2 years ( 4 months to 17 years). Immunosuppressive protocols included a sequential quadruple therapy regiment. At the time of GFR estimation, immunosuppressive drugs included steroids for 81 recipients, calcineurin inhibitors for 86 recipients (45 cyclosporine and 41 tacrolimus), sirolimus for 9 and mycophenolate mofetil or mycophenolate sodium for 80 patients. All patients were of Caucasian origin. This prospective study was performed simultaneously with renal hemodynamic monitoring as a part of our routine transplant follow up and quality assurance process. In accordance with French law, samples collected for this study were registered at the Ministère de l'Enseignement Supérieur et de la Recherche with the number DC-2008-417 after approval by our institution's ethical committee. Method comparison was performed only between the 
PETIA method used on the SPAPLUS ${ }^{\circledR}$ analyzer (Cystatin C latex reagents, Binding Site, Birmingham, UK) and the Siemens-PENIA application on the BNII ${ }^{\circledR}$ nephelometer and the Dako-PETIA application on the Olympus AU640 ${ }^{\circledR}$ analyzer.

\section{Impact of the assay on GFR estimation}

GFR was measured by urinary clearance of technetium-labeled diethylene-triaminopentaacetic $\left(99^{\mathrm{m}}\right.$ Tc-DTPA) using the constant infusion technique, as previously described (7). Briefly, after the induction of water diuresis and a 90-min equilibration period, four 20- to 30min urine collections were obtained by spontaneous voiding. The measured GFR (mGFR) was the average of four measurements. Values were expressed as $\mathrm{mL} / \mathrm{min}$ per $1.73 \mathrm{~m}^{2}$.

On the day of the ${ }^{99 \mathrm{~m}} \mathrm{Tc}-\mathrm{DTPA}$ GFR measurement, patients had a blood sample taken for routine parameters and the remaining plasma was stored at $-80^{\circ} \mathrm{C}$ for cystatin $\mathrm{C}$ determination. Height and weight were recorded. Plasma creatinine was measured using an enzymatic ID-MS traceable assay on the Olympus analyzer (Olympus France, Rungis, France) using creatinine reagent from Randox (Randox, Mauguio, France) (8). This method has been previously validated against the enzymatic Roche assay (8) used for the 175 MDRD equation (9).

GFR was estimated with the IDMS traceable creatinine based equation: the simplified 175 MDRD formula (9) :

GFR $=175 \times(\text { creatinine })^{-1.154} \times(\text { age })^{-0.203} \times(0.742$, if patient is female $) \times(1.21$, if patient is black)

Furthermore, GFR was calculated according to cystatin C-based GFR formulas described by Stevens et al (3) using:

cystatin $\mathrm{C}$ alone

GFR $=76.7 \times(\text { serum cystatin } C)^{-1.19}$ 
cystatin $\mathrm{C}$ in combination with creatinine and demographic coefficients (age, sexe, race)

GFR $=177.6 \times(\text { creatinine })^{-0.65} \times(\text { cystatin } C)^{-0.57} \times(\text { age })^{-0,20} \times(0,82$ if woman $) \times(1,11$ if black)

\section{Statistical Analysis}

Linear regression analysis was performed to compare data from the different methods used for Cystatin $\mathrm{C}$ determinations. In addition, according to recommendations for method comparison studies, the scatter of differences was visualized according to Bland-Altman analysus.

Bland and Altman analysis were also performed to evaluate the performance of the equations. Bias was defined as the mean difference between the measured GFR $\left({ }^{99 \mathrm{~m}} \mathrm{Tc}-\mathrm{DTPA}\right)$ and estimated GFR. Precision was defined as the SD of the difference between the measured and estimated GFR. Accuracy (P30) was defined according to the K/DOQI as the percentage of GFR estimates included within $30 \%$ of the measured GFR (using ${ }^{99 \mathrm{~m}}$ Tc-DTPA). 


\section{Results}

\section{Analytical performances}

Total intra-assay CVs for the cystatin C low control (target value: $1.01 \mathrm{mg} / \mathrm{L}$ ) were $4.4 \%$, and $3.7 \%$ on the $\mathrm{SPA}_{\mathrm{PLUS}}{ }^{\circledR}$ and Hitachi ${ }^{\circledR}$ analyzer, respectively. Total inter-assay CVs were $4.6 \%$ and $3.5 \%$ on the SPAPLUS ${ }^{\circledR}$ and Hitachi ${ }^{\circledR}$ analyzers, respectively. The coefficient of linearity yielded $r=0.99\left(\mathrm{y}=0.99 \mathrm{x}+0.08\right.$ and $\mathrm{y}=0,96 \mathrm{x}+0.16$ on $\mathrm{SPA}_{\mathrm{PLUS}}{ }^{\circledR}$ and Hitachi ${ }^{\circledR}$ analyzer respectively). Correlation between serum cystatin $\mathrm{C}(\mathrm{x})$ and heparinized plasma cystatin $\mathrm{C}(\mathrm{y})$ showed a correlation coefficient $(r)$ of 0.98 (plasma Cyst $\mathrm{C}=0.95$ serum Cyst $\mathrm{C}+0.11$ ).

\section{Panel Measurement}

Since no reference method and/or material were available at the time of our study for cystatin C measurements, we chose to estimate the 'true' value of each pool using the mean of the results obtained with all the methods tested (10). Considering the mean of the methods as the reference value, Binding Site on the SPAPLUS ${ }^{\circledR}$ and Dako measured with the Olympus AU640 ${ }^{\circledR}$ tend to overestimate results, while Binding Site using the Hitachi ${ }^{\circledR}$ and Siemens with BN II ${ }^{\circledR}$ tend to underestimate results (Table 1). Differences between methods are not only dependent on the source of the antibodies, but also are related to the application on a specific instrument. To underline the importance of the "reagent-instrument" combination, it is important to note that differences of $0.13 \mathrm{mg} / \mathrm{L}(19.9 \%), 0.11 \mathrm{mg} / \mathrm{L}(13.1 \%), 0.14 \mathrm{mg} / \mathrm{L}$ (15.3\%), 0.19mg/L (14.5\%) and 0.28mg/L (19.6\%) for levels 1, $2,3,4$ and 5, respectively, were observed using the same antibody (monospecific sheep antibody) on two different instruments (SPAPLUS ${ }^{\circledR}$ and Hitachi $\left.{ }^{\circledR}\right)$.

\section{Method comparison}

Regression analysis between Siemens (x) and Binding Site on $\operatorname{SPA}_{\mathrm{PLuS}}{ }^{\circledR}$ (y) showed a correlation coefficient $\left(r^{2}\right)$ of $0.89\left(\right.$ SPAPLUS $^{\circledR}=1.08$ Siemens +0.20$)$. Similarly, regression 
analysis between Dako-Olympus (x) and Binding Site on $\mathrm{SPAPLuS}^{\circledR}(\mathrm{y})$ showed a correlation coefficient $\left(\mathrm{r}^{2}\right)$ of $0.92\left(\mathrm{SPA}_{\mathrm{PLUS}}{ }^{\circledR}=1.21\right.$ Dako -0.03$)$. In addition, the mean value and standard deviation of the differences according to Bland-Altman analysis was $0.33 \pm 0.21$ and $0.32 \pm 0.21$ for the Siemens PENIA and the Dako-Olympus PETIA methods, respectively (Figure 1).

\section{Impact on GFR Estimation using Binding Site reagents}

The mean measured GFR using $99^{\mathrm{m}}$ TcDTPA was $49.2 \pm 20.1 \mathrm{ml} / \mathrm{min} / 1.73 \mathrm{~m}^{2}$ (median 47.5 [8.3-110.9] $\left.\mathrm{ml} / \mathrm{min} / 1.73 \mathrm{~m}^{2}\right)$, including 21 patients with a GFR $>60 \mathrm{ml} / \mathrm{min} / 1.73 \mathrm{~m}^{2}(5$ stage $1 \mathrm{~T}$ patients and 16 stage $2 \mathrm{~T}$ patients), 61 patients with a GFR between 30 and $60 \mathrm{ml} / \mathrm{min} / 1.73 \mathrm{~m}^{2}$ (stage 3T) and 17 patients with a GFR $<30 \mathrm{ml} / \mathrm{min} / 1.73 \mathrm{~m}^{2}$ (14 stage $4 \mathrm{~T}$ and 3 stage $5 \mathrm{~T}$ ).

Table 2 shows the bias, precision, accuracy and the percentage of kidney transplants correctly classified into the K/DOQI CKD stage according to each predictive equation tested. Regarding creatinine based equations, the simplified 175 MDRD classified $81.8 \%$ of kidney transplants within $30 \%$ of the measured GFR. The cystatin $\mathrm{C}$ based equation showed a bias of $9.1 \mathrm{ml} / \mathrm{min} / 1.73 \mathrm{~m}^{2}$, a precision of $11.9 \mathrm{ml} / \mathrm{min} / 1.73 \mathrm{~m}^{2}$ and an accuracy P30 of $71.7 \%$. When SPAPLUS $^{\circledR}$ cystatin C results were corrected according to the correlation equation $\left(\mathrm{SPA}_{\mathrm{PLUS}}{ }^{\circledR}=\right.$ 1.08 Siemens +0.20$)$, the accuracy was enhanced further $(\mathrm{P} 30=78.8 \%)$. The combined cystatin-creatinine based equation showed a bias of $5.6 \mathrm{ml} / \mathrm{min} / 1.73 \mathrm{~m}^{2}$ and precision of 9.5 $\mathrm{ml} / \mathrm{min} / 1.73 \mathrm{~m}^{2}$. The percentage of patients within $30 \%$ of the measured GFR was $83.8 \%$ using cystatin $\mathrm{C}$ crude values and $81.8 \%$ using cystatin $\mathrm{C}$ corrected values. The combined equation classified $70.7 \%$ of the patients into the correct CKD stage using crude cystatin C crude and $75.7 \%$ using cystatin C corrected values. 


\section{Discussion}

In this study, we demonstrated that a new assay using Cystatin $\mathrm{C}$ reagents from Binding Site in a PETIA application on the SPAPLUS $^{\circledR}$ and Hitachi ${ }^{\circledR}$ analyzers exhibited reliable performance. The values obtained with the Binding Site assay on the SPAPLUS ${ }^{\circledR}$ were correlated with the Siemens-PENIA and the Dako-Olympus PETIA methods, although with a positive bias of approximately $0.3 \mathrm{mg} / \mathrm{L}$. The creatinine and cystatin $\mathrm{C}$ based equations allowed reliable assessment of GFR in our population of renal transplant recipients.

When we used the same Binding Site antibodies on 2 different analyzers (SPAPLus ${ }^{\circledR}$ and Hitachi $^{\circledR}$ ) according to the manufacturer's recommendations, a discrepancy of up to $0.28 \mathrm{mg} / \mathrm{L}$ for the highest cystatin $\mathrm{C}$ concentration was observed. Interestingly, it seems that Hitachi ${ }^{\circledR}$ is closer to the Siemens PENIA method, while the SPAPLus ${ }^{\circledR}$ is close to the Dako PETIA method on the Olympus ${ }^{\circledR}$. Similar variations have been observed previously using the same antibody from Dako with different instrument and assay protocols (11).

Further comparison studies were performed with the SPAPLUS ${ }^{\circledR}$ analyzer only. Our data showed a mean difference of $0.33 \pm 0.21 \mathrm{mg} / \mathrm{L}$ between the SPAPLUS ${ }^{\circledR}$ and Siemens PENIA and $0.32 \pm 0.21 \mathrm{mg} / \mathrm{L}$ between SPAPLUS ${ }^{\circledR}$ and Dako PETIA. However, these biases are difficult to interpret in the absence of a reference method. At the time of this study, there was no standardization of cystatin C measurements. Depending on the application, two calibrators can be used i) a delipidated human serum pool spiked with human cystatin C for Gentian and DakoCytomation ii) lyophilized polygeline with human urine proteins for Siemens. The Binding Site application uses pooled human serum. Since a primary reference preparation has been produced (12), the availability of recombinant human cystatin $\mathrm{C}$ might reduce such problems. This evaluation of bias is of particular importance to assess the transferability of automated methods for cystatin C measurements. Previous method comparisons demonstrated 
some discrepancies related both to the source of the antibodies (Siemens, Dako, Gentian) or to adaptation of the method to different instruments $(11,13,14)$.

Also, we compared different formulas for estimating GFR based on creatinine, cystatin $\mathrm{C}$ and a combination of creatinine and cystatin in renal transplant recipients (3). In order to overcome analytical limitations, both crude Binding Site SPAPLus ${ }^{\circledR}$ cystatin $\mathrm{C}$ values and corrected values, according to the correlation equation $\left(\mathrm{SPA}_{\mathrm{PLUS}}{ }^{\circledR}=1.08\right.$ Siemens +0.20$)$, were used in GFR prediction algorithms (Table 2). MDRD 175, cystatin C alone or combined equations allowed for accurate assessment of GFR (P30\% around 80\%). Moreover, cystatin C and combined equations provided better classification of kidney transplant patients in different stages of chronic kidney disease (from 70.7 to 75.7\%) compared with MDRD 175.

In transplant patients, the limitations of creatinine for the detection of kidney failure and estimation of GFR have been related primarily to immunosuppressive treatment $(15,16)$. Corticosteroids have a negative influence on muscle mass (17), and cyclosporine can modify the tubular secretion of creatinine, resulting in overestimation of GFR (18). As previously reported in a selected population with abnormal muscle mass and early detection of acute kidney injury (19), cystatin C rather than creatinine could be a more appropriate marker for the estimation of GFR and the detection of renal allograft deterioration. However, in renal transplantation, previous data are inconsistent. Some authors found cystatin $\mathrm{C}$ to improve sensitivity (20-22), whereas others found that the diagnostic performance, as assessed by ROC curve analysis, does not differ significantly between the two markers, especially at the critical GFR threshold of $60 \mathrm{~mL} / \mathrm{min}(23,24)$. These conflicting results could be due either to confounding factors interfering in the transplant population, or to the lack of cystatin assay standardization. Indeed, it has been suggested that steroïds increase serum cystatin $C(4,15$, 25) leading to an underestimation of GFR. However, in our cohort, 18 patients did not receive 
any steroïds, 40 received $5 \mathrm{mg} /$ day of prednisolone or less, an 41 received between 7.5 and 20 $\mathrm{mg} /$ day.

Our study has some limitations. First, as reported in previous work, lack of standardization for cystatin $\mathrm{C}$ measurement leading to assay-specific cystatin based equations for eGFR represents the main limitation $(11,13,14)$. Most formula have been developed with Dako or Siemens cystatin C methods (3-6). Using Dako or Siemens cystatin C in a formula lead to comparable bias $\left(1 \mathrm{~mL} / \mathrm{min} / 1.73 \mathrm{~m}^{2}\right)$ and precision $\left(10 \mathrm{~mL} / \mathrm{min} / 1.73 \mathrm{~m}^{2}\right)$. Accuracy ranges between 81 and $84 \%$, and the percentage of patients correctly classified into the correct K/DOQI CKD stage ranged between 71 and $76 \%$ for Dako and Siemens cystatin C methods, respectively (data not shown). Since no equation was available for the Binding Site assay, we decided to use Binding Site cystatin $\mathrm{C}$ corrected values in the published Siemens equations (3). Second, enzymatic ID-MS traceable creatinine measurement alone results in the classification of $62.6 \%$ of patients into the correct K/DOQI CKD stages. Daily creatinine could be performed easily to assess any relative change in GFR $(26,27)$, raising the question of the relative advantage of cystatin $\mathrm{C}$ measurements. The cystatin $\mathrm{C}$ based or the combined equation moderately improved determination of GFR (about 10\% compared to 175MDRD for classification into the correct $\mathrm{K} / \mathrm{DOQI} \mathrm{CKD}$ stage). This observation could suggest that benefits from the use of an combined equation based on creatinine plus cystatin $\mathrm{C}$ are greater than the shortcomings derived from the use of an equation that adds the imprecision of 2 analytical methods (creatinine and cystatin C). The clinical relevance of this eGFR improvement, especially in long term monitoring, deserves further analysis. Standardization of cystatin $\mathrm{C}$ determination using reference material and improvement of cystatin $\mathrm{C}$ analytical performance could extend the use of cystatin $\mathrm{C}$ based equations for determination of GFR. 
In conclusion, Cystatin $\mathrm{C}$ measurements using Binding Site reagents have reliable analytical performance. As previously suggested (28), the use of cystatin C in a combined equation with creatinine could improve the accuracy of eGFR algorithms in renal transplant recipients. However, this result is obtained primarily using corrected cystatin $\mathrm{C}$ values. Standardization of Cystatin $\mathrm{C}$ assays and a better understanding of potential confounding factors of cystatin levels in transplantation could further improve the value of cystatin $\mathrm{C}$. 


\section{References}

1. Séronie-Vivien S, Delanaye P, Piéroni L, Mariat C, Froissart M, Cristol JP; SFBC "Biology of renal function and renal failure" working group. Cystatin C: current position and future prospects. Clin Chem Lab Med 2008;46:1664-86.

2. Zahran A, El-Husseini A, Shoker A. Can cystatin C replace creatinine to estimate glomerular filtration rate? A literature review. Am J Nephrol 2007;27:197-205.

3. Stevens LA, Coresh J, Schmid CH, Feldman HI, Froissart M, Kusek J et al. Estimating GFR using serum cystatin $\mathrm{C}$ alone and in combination with serum creatinine: a pooled analysis of 3,418 individuals with CKD. Am J Kidney Dis 2008;51:395-406.

4. Rule AD, Bergstralh EJ, Slezak JM, Bergert J, Larson TS. Glomerular filtration rate estimated by cystatin C among different clinical presentations. Kidney Int 2006;69:399-405.

5. Grubb A, Nyman U, Björk J, Lindström V, Rippe B, Sterner G et al. Simple cystatin Cbased prediction equations for glomerular filtration rate compared with the modification of diet in renal disease prediction equation for adults and the Schwartz and the Counahan-Barratt prediction equations for children. Clin Chem 2005;51:1420-31.

6. Larsson A, Malm J, Grubb A, Hansson LO. Calculation of glomerular filtration rate expressed in $\mathrm{mL} / \mathrm{min}$ from plasma cystatin $\mathrm{C}$ values in $\mathrm{mg} / \mathrm{L}$. Scand $\mathrm{J}$ Clin Lab Invest $2004 ; 64: 25-30$.

7. Vetromile F, Szwarc I, Garrigue V, Delmas S, Fesler P, Mimran A et al. Early high pulse pressure is associated with graft dysfunction and predicts poor kidney allograft survival. Transplantation 2009;88:1088-94.

8. Badiou S, Dupuy AM, Descomps B, Cristolead JP. Comparison between the enzymatic vitros assay for creatinine determination and three other methods adapted on the Olympus analyzer. J Clin Lab Anal 2003;17:235-40. 
9. Levey AS, Coresh J, Greene T, Marsh J, Stevens LA, Kusek JW et al. Expressing the Modification of Diet in Renal Disease Study equation for estimating glomerular filtration rate with standardized serum creatinine values. Clin Chem 2007;53:766-772.

10. Cavalier E, Rozet E, Carlisi A, Bekaert AC, Rousselle O, Hubert P et al. Analytical validation of serum bone alkaline phosphatase (BAP OSTASE) on Liaison. Clin Chem Lab Med 2010;48:67-72.

11. Flodin M, Hansson LO, Larsson A. Variations in assay protocol for the Dako cystatin C method may change patient results by $50 \%$ without changing the results for controls. Clin Chem Lab Med 2006; 44:1481-1485.

12. Blirup-Jensen S, Grubb A, Lindstrom V, Schmidt C, Althaus H. Standardization of Cystatin C: development of primary and secondary reference preparations. Scand J Clin Lab Invest Suppl 2008;241:67-70.

13. Li J, Dunn W, Breaud A, Elliott D, Sokoll LJ, Clarke W. Analytical Performance of 4 Automated Assays for Measurement of Cystatin C. Clin Chem 2010;[Epub ahead of print].

14. Delanaye P, Pieroni L, Abshoff C, Lutteri L, Chapelle JP, Krzesinski JM et al. Analytical study of three cystatin C assays and their impact on cystatin C-based GFR-prediction equations. Clin Chim Acta. 2008;398:118-24.

15. Risch L, Herklotz R, Blumberg A, Huber AR. Effects of glucocorticoid immunosuppression on serum cystatin $\mathrm{C}$ concentrations in renal transplant patients. Clin Chem 2001;47:2055-9.

16. Pöge U, Stoschus B, Stoffel-Wagner B, Gerhardt T, Klehr HU, Sauerbruch T et al. Cystatin $\mathrm{C}$ as an endogenous marker of glomerular filtration rate in renal transplant patients. Kidney Blood Press Res 2003;26:55-60.

17. Kasiske BL. Creatinine excretion after renal transplantation. Transplantation 1989;48:4248. 
18. Tomlanovich S, Golbetz H, Perlroth M, Stinson E, Myers BD. Limitations of creatinine in quantifying the severity of cyclosporine-induced chronic nephropathy. Am J Kidney Dis $1986 ; 8: 332-7$.

19. Herget-Rosenthal S, Bökenkamp A, Hofmann W. How to estimate GFR-serum creatinine, serum cystatin C or equations? Clin Biochem. 2007;40:153-61.

20. Christensson A, Ekberg J, Grubb A, Ekberg H, Lindström V, Lilja H. Serum cystatin C is a more sensitive and more accurate marker of glomerular filtration rate than enzymatic measurements of creatinine in renal transplantation. Nephron Physiol 2003;94:19-27.

21. White C, Akbari A, Hussain N, Dinh L, Filler G, Lepage N et al. Estimating glomerular filtration rate in kidney transplantation: a comparison between serum creatinine and cystatin C-based methods. J Am Soc Nephrol 2005;16:3763-70.

22. Maillard N, Mariat C, Bonneau C, Mehdi M, Thibaudin L, Laporte S et al. Cystatin Cbased equations in renal transplantation: moving toward a better glomerular filtration rate prediction? Transplantation 2008;85:1855-8.

23. Pöge U, Gerhardt T, Stoffel-Wagner B, Palmedo H, Klehr HU, Sauerbruch T et al. Prediction of glomerular filtration rate in renal transplant recipients: cystatin $\mathrm{C}$ or modification of diet in renal disease equation? Clin Transplant 2006;20:200-5.

24. Zahran A, Qureshi M, Shoker A. Comparison between creatinine and cystatin C-based GFR equations in renal transplantation. Nephrol Dial Transplant. 2007;22:2659-68.

25. Pöge U, Gerhardt T, Bökenkamp A, Stoffel-Wagner B, Klehr HU, Sauerbruch T et al. Time course of low molecular weight proteins in the early kidney transplantation period-influence of corticosteroids. Nephrol Dial Transplant. 2004;19:2858-63.

26. Myers GL, Miller WG, Coresh J, Fleming J, Greenberg N, Greene $\mathrm{T}$ et al. Recommendations for improving serum creatinine measurement: a report from the laboratory working group of the national kidney disease education program. Clin Chem 2006;52:5-18. 
27. Kidney Disease: Improving Global Outcomes (KDIGO) Transplant Work Group. KDIGO clinical practice guideline for the care of kidney transplant recipients. Am J Transplant. 2009;9:S1-155.

28. White CA, Akbari A, Doucette S, Fergusson D, Knoll GA. Estimating glomerular filtration rate in kidney transplantation: is the new chronic kidney disease epidemiology collaboration equation any better? Clin Chem 2010; 56:474-7.

\section{Conflict of interest : none}




\section{Tables}

Table 1. Panel Determination. Comparison between cystatin $\mathrm{C}$ measurements and the mean of the methods (mean value, mg/L). Results are expressed as percentage of under or overestimation.

\begin{tabular}{|l|l|l|l|l|l|}
\hline & $\begin{array}{l}\text { Mean value, } \\
\mathrm{mg} / \mathrm{L}\end{array}$ & $\begin{array}{l}\text { Siemens on } \\
\text { BNII }^{\circledR}, \%\end{array}$ & $\begin{array}{l}\text { Binding Site on } \\
\text { Hitachi }^{\circledR}, \%\end{array}$ & $\begin{array}{l}\text { Binding Site on } \\
\text { SPAPLUS }^{\circledR}, \%\end{array}$ & $\begin{array}{l}\text { Dako on Olympus } \\
\text { AU640 }^{\circledR}, \%\end{array}$ \\
\hline Pool 1 & 0.73 & -16.9 & -7.0 & 11.5 & 12.4 \\
\hline Pool 2 & 0.83 & -16.2 & -2.5 & 10.2 & 8.5 \\
\hline Pool 3 & 0.95 & -15.5 & -3.2 & 11.7 & 7.0 \\
\hline Pool 4 & 1.35 & -16.2 & -3.1 & 11.0 & 8.4 \\
\hline Pool 5 & 1.56 & -16.4 & -7.0 & 11.2 & 12.2 \\
\hline
\end{tabular}

Table 2. Bias, precision, accuracy and percentage of patients correctly classified into the correct K/DOQI CKD stage, as determined by the measured $99^{\mathrm{m}}$ Tc-DTPA GFR.. Values in brackets represent the results obtained with Binding Site SPAPLUS ${ }^{\circledR}$ cystatin corrected values according to the correlation equation $\left(\mathrm{SPA}_{\mathrm{PLUS}}{ }^{\circledR}=1.08\right.$ Siemens +0.20$)$.

\begin{tabular}{|l|l|l|l|l|}
\hline & $\begin{array}{l}\text { Bias, } \\
\mathrm{ml} / \mathrm{min} / 1.73 \mathrm{~m}^{2}\end{array}$ & $\begin{array}{l}\text { Precision, } \\
\mathrm{ml} / \mathrm{min} / 1.73 \mathrm{~m}^{2}\end{array}$ & $\begin{array}{l}\text { Accuracy } \\
30 \%, \%\end{array}$ & $\begin{array}{l}\% \text { of patients correctly } \\
\text { classified into the correct } \\
\text { K/DOQI CKD stage }\end{array}$ \\
\hline & Creatinine based equation : MDRD 175 \\
\hline & 2.6 & 10.9 & 81.8 & 62.6 \\
\hline Cystatin based equation & $71.7(78.8)$ & $64.6(70.7)$ \\
\hline & $9.1(-3.5)$ & $11.9(15.9)$ & $70.7(75.7)$ \\
\hline
\end{tabular}




\section{Figures}

Figure 1. Correlation and Bland-Altman representation for Cystatin C Binding Site SPAPLUS ${ }^{\circledR}$

A) vs. Cystatin C Siemens (PENIA)
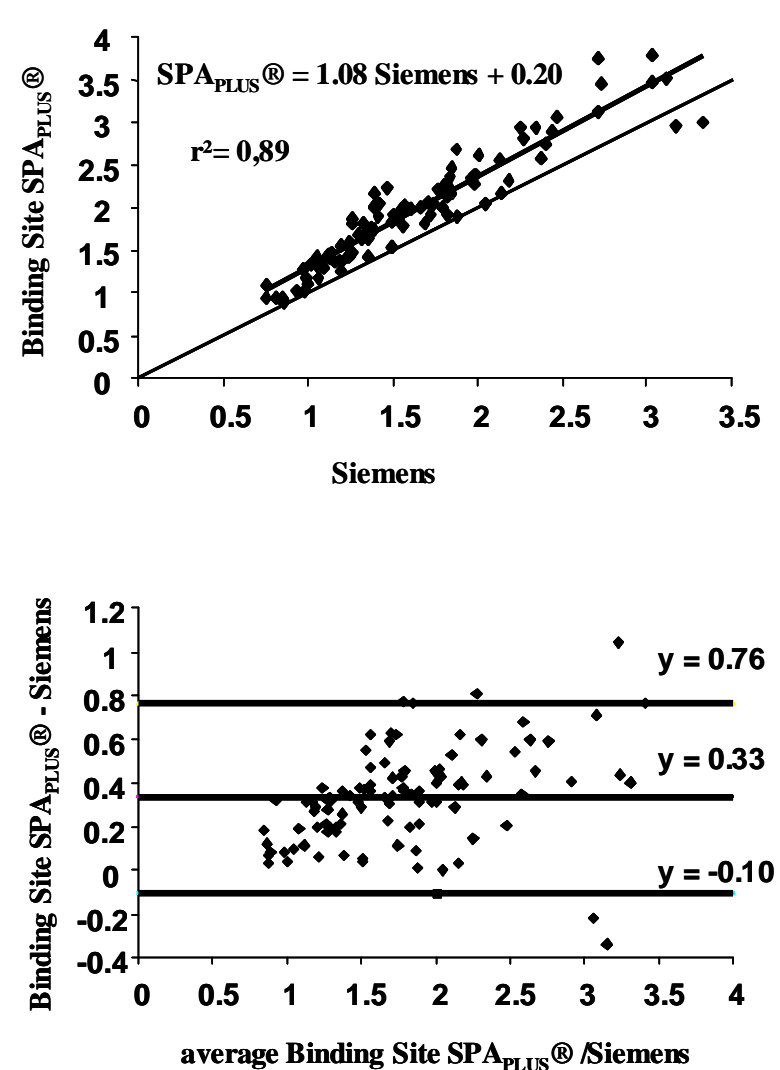

B) vs. Cystatin C Dako (PETIA)
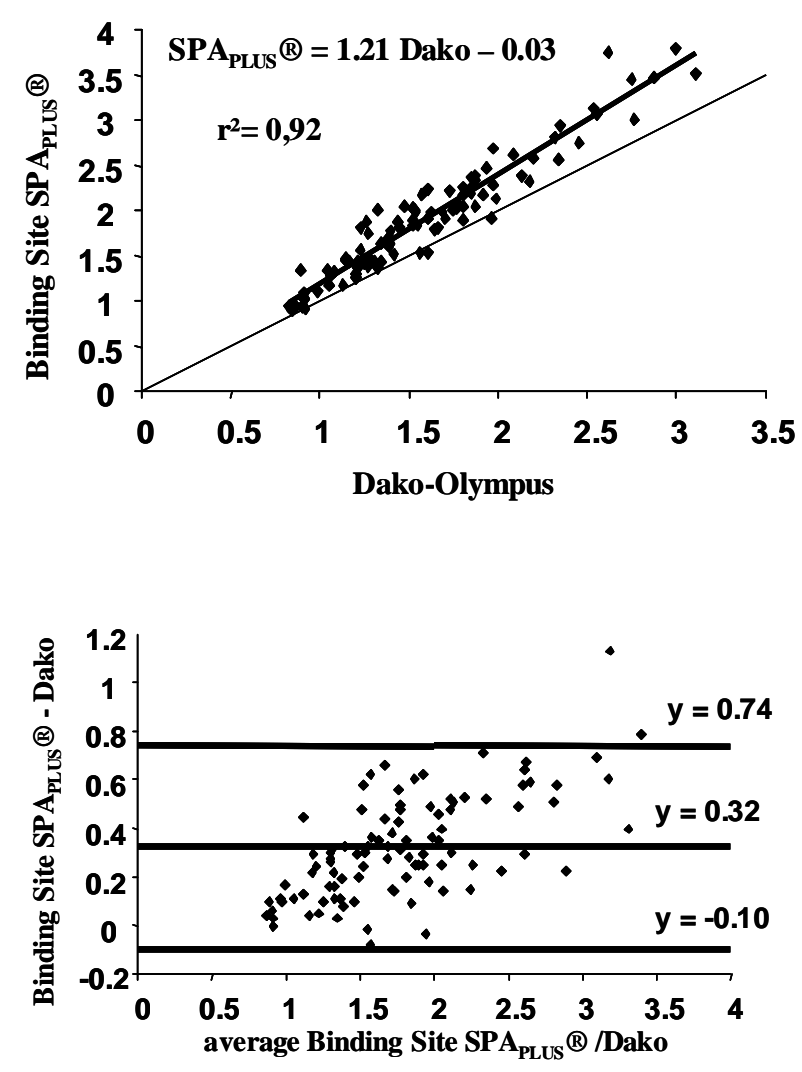